\title{
An ontology based modeling framework for design of educational technologies
}

\author{
Sridhar Chimalakonda ${ }^{1 *}$ (D) and Kesav V. Nori ${ }^{2}$
}

\author{
* Correspondence: ch@iittp.ac.in \\ This work was carried out as part of \\ first author's doctoral thesis at IIIT \\ Hyderabad, India and contains \\ content from the thesis \\ Chimalakonda (2017). \\ ${ }^{1}$ Department of Computer Science \\ \& Engineering, IIT Tirupati, Tirupati, \\ India \\ Full list of author information is \\ available at the end of the article
}

\begin{abstract}
Despite rapid progress, most of the educational technologies today lack a strong instructional design knowledge basis leading to questionable quality of instruction. In addition, a major challenge is to customize these educational technologies for a wide range of customizable instructional designs. Ontologies are one of the pertinent mechanisms to represent instructional design in the literature. However, existing approaches do not support modeling of flexible instructional designs. To address this problem, in this paper, we propose an ontology based framework for systematic modeling of different aspects of instructional design knowledge based on domain patterns. As part of the framework, we present ontologies for modeling goals, instructional processes and instructional material. We demonstrate the ontology framework by presenting instances of the ontology for the large scale case study of adult literacy in India (287 million learners spread across 22 Indian Languages), which requires creation of hundreds of similar but varied eLearning Systems based on flexible instructional designs. The implemented framework is available at http://rice. iiit.ac.in and is transferred to National Literacy Mission Authority of Government of India. The proposed framework could be potentially used for modeling instructional design knowledge for school education, vocational skills and beyond.
\end{abstract}

Keywords: Scale, Variety, Educational technologies, Ontologies, Instructional design, Goals, Instructional process, Content, eLearning systems

\section{Motivation \& case study}

There are 287 million adult illiterates in India spread across 22 Indian Languages who can speak the language, but cannot read or write (UNESCO, 2014). The National Literacy Mission (NLM) of Government of India (GoI) has come up with a uniform methodology called Improved Pace and Content of Learning (IPCL) to teach adult illiterates across India (DAE, 2003). Based on this methodology, the State Resource Centres $(\mathrm{SRCs})^{1}$ have created customized instructional designs for teaching 3Rs (Reading, wRiting and aRtithmetic) with varied goals, teaching styles, learning styles, content catering

\footnotetext{
"SRCs provide academic and technical resource support to adult and continuing education through development and production of material and training modules", https://mhrd.gov.in/state_resource_centre
} 
to the varying needs of local contexts. This process has produced hundreds of primers ${ }^{2}$ catering to varied needs across 22 Indian Languages.

On the other hand, huge scarcity of qualified teachers and the need to address large scale and variety of contexts has led to use of a wide range of technologies for adult literacy in India (Chimalakonda \& Nori, 2013; CSR, TCS, 2016; Deshpande, Desrochers, Ksoll, \& Shonchoy, 2017; Patel, 2002).

However, the design, development and customization of a large scale and variety of $e$ Learning Systems ${ }^{3}$ for adult literacy in India is a hard challenge from two perspectives (Chimalakonda, 2017) (i) support flexible instructional designs (ii) effort to create and maintain $e$ Learning Systems. In this paper, we focus on modeling the scale and variety of instructional design knowledge that includes context, goals, process, content, evaluation and environment (Chimalakonda \& Nori, 2018). We do not attempt to model the entire instructional knowledge but a subset of this knowledge within the scope of the adult literacy case study focusing on instructional design variants. Also, our research relies on (i) IPCL, a pedagogy and a process for teaching 3Rs to adult illiterates and which provides guidelines to prepare instructional materials across multiple languages and varied contexts (DAE, 2003) (ii) field-tested eLearning systems based on these instructional materials (iii) domain specific patterns of instructional design (Chimalakonda, 2017; Chimalakonda \& Nori, 2014, 2018). Based on synthesis of existing literature and our experience with adult literacy domain, the requirements for knowledge representation in adult literacy are as follows:

- in synergy with instructional design

- machine-processable

- facilitate reuse and semi-automatic design of eLearning Systems

- able to support sharing of knowledge between different applications and tools

With this background, the research questions of this paper are:

- What is the knowledge that is required to facilitate the design and development of eLearning systems for scale and variety in the context of adult literacy in India?

- How to represent this knowledge in order to customize these eLearning Systems for flexible instructional designs?

In the next section, we review literature on modeling instructional design knowledge.

\section{Related work}

Researchers have figured out multiple ways of representing knowledge such as concept maps, topic maps, ontologies, first order logic and so on (Baral \& De Giacomo, 2015; Buitrago \& Chiappe, 2019; Sowa, 1999). In this section, we discuss the work that is related to the proposed research.

\footnotetext{
${ }^{2}$ Primers are essentially printed textbooks based on customized instructional designs.

${ }^{3}$ We consider eLearning Systems (iPrimers) for adult literacy as simple multimedia systems that use audio and visual aspects to teach reading, writing and basic arithmetic corresponding to physical instructional material, scale refers to number of systems and variety represents different kinds of systems. (Chimalakonda, 2017)
} 


\section{Ontologies for instructional design}

Ontologies have gained immense importance as one of the widely used methods to represent and share knowledge in several domains such as software engineering (Happel, Maalej, \& Seedorf, 2010; Tebes et al., 2019), enterprise modeling (Pinto, de Rezende Rohlfs, \& Parreiras, 2014), requirements engineering (Dermeval et al., 2016). These ontologies are of different kinds ranging from informal light weight ontologies to formal ontologies depending on the degree of formalism and the power of expressivity (Giunchiglia \& Zaihrayeu, 2009). Happel et al. (2010) have detailed the advantages of ontologies over conceptual models and meta-models. According to Fensel (2001), the promise of ontologies to provide "a shared and common understanding of a domain that can be communicated between people and application systems" is one of the primary reasons for their popularity. This can be construed as representation, communication and automation needs for scale and variety in the design of educational technologies. In education domain, ontologies are used in a wide range of applications ranging from explicit representation of domain knowledge to automatic generation of personalized content (Sampson, Lytras, Wagner, \& Diaz, 2004; Mizoguchi \& Bourdeau, 2016; Tapia-Leon, Rivera, Chicaiza, \& Luján-Mora, 2018; Yago, Clemente, Rodriguez, \& Fernandez-de Cordoba, 2018; Stancin, Poscic, \& Jaksic, 2020). Mizoguchi and Bourdeau (2016) have identified four key requirements of instructional authoring systems (i) adaptivity (ii) explicit conceptualization (iii) standardization to facilitate reuse (iv) theory-awareness. Based on this analysis, the authors proposed knowledge and ontological engineering as a potential solution to cater to these requirements.

One particular use of ontologies is to model instructional design theories and learning designs (Psyché, Bourdeau, Nkambou, \& Mizoguchi, 2005) but in this paper, we are interested from educational technologies perspective. The MISA method provides an engineering approach for modeling knowledge in learning systems (Aubin \& Crevier, 1999). The learning system itself is considered as consisting of a knowledge model, pedagogical model and media model to represent different aspects (Aubin \& Crevier, 1999). However, the concepts are not explicitly modeled as ontologies. A 10-year research effort has resulted in creating a comprehensive ontology covering instructional design knowledge for various instructional theories and adhering to learning design standards (Mizoguchi, Hayashi, \& Bourdeau, 2007). SMARTIES is a scenario-based instructional authoring tool based on this ontology and advocates the design of educational technologies based on educational theories modeled as ontologies to facilitate quality of instruction (Bourdeau, Mizoguchi, Hayashi, Psyche, \& Nkambou, 2007). However, as analyzed and reported by Kasai, Nagano, and Mizoguchi (2011), the inherent complexity of the ontology and SMARTIES tool are primarily useful for expert teachers. ON-SMMILE is an ontology network that focuses on modeling students learning' for recommendation of competencies (Yago et al., 2018). Barbagallo and Formica (2017) have integrated ontologies and semantic search to improve e-learning technologies in the domain of continuing education. Challco, Bittencourt, and Isotani (2020) have proposed ontologies to support gamification of scripted collaborative learning sessions.

While focusing on quality of instruction is one aspect, using ontologies in education to facilitate reuse is another critical research direction that received significant attention in the literature (Mizoguchi \& Bourdeau, 2016). Devedzic (1999) explored the notion of 
ontologies for intelligent tutoring systems (ITS) based on inspiration from software patterns as early as 1999. Recently, Chang et al. (2020) have proposed an ontology based approach that uses data mining to generate tutoring models for ITS. Ontologies are used as a basis for automating the development of gamified intelligent tutoring systems (Dermeval et al., 2017).

George and Lal (2019) summarizes existing research in the field of ontologybased recommender systems and specifically on personalization in e-learning. Ontology-based tools for learning systems are prevalent in the literature (Bouihi \& Bahaj, 2019; Haendler \& Neumann, 2019; Leo et al., 2019; Cubric \& Tosic, 2020).

The EDUC8 ontology aims at modeling domain knowledge for multiple student learning pathways (Iatrellis, Kameas, \& Fitsilis, 2019). Miranda, Orciuoli, Loia, and Sampson (2017) have presented an ontology-based model for competency management. Ibrahim, Yang, Ndzi, Yang, and Al-Maliki (2018) presents an ontology-based personalized course recommendation framework that combines collaborative-based filtering with content-based filtering while choosing courses and jobs. Sarwar, Qayyum, GarcíaCastro, Safyan, and Munir, (2019) is another direction that proposes a CourseOntology which recommends adaptive content based on categorization of learner profiles.

Verbert, Klerkx, Meire, Najjar, and Duval (2004) proposed ontologies to formalize learning object content models. To facilitate flexible content reuse, the Abstract Learning Object Content Model (ALOCoM) ontology and a set of supporting tools were proposed by Verbert et al. (2004). Amorim, Lama, Sánchez, Riera, and Vila (2006) have proposed a learning design ontology based on IMS Learning Design (IMS-LD) specification through a set of 20 design and run time axioms. The basic premise of this ontology was to explicitly and precisely address the drawbacks of IMS-LD specification. But isolated research on learning objects and learning designs have made reuse difficult motivating the need for a bridge ontology focusing on context (Knight, Gasevic, \& Richards, 2006). Verón, Celeste, Alejandra, and de los Milagros (2016) present an interoperability model based on ontologies for learning object repositories. Vidal-Castro, Sicilia, and Prieto (2012) proposed a formal ontology for representing instructional design methods and provide a rule catalogue to verify the conformance of ontologies for a particular instructional design theory. However, these ontologies are not based on domain-specific patterns, which is the case in this paper.

The primary motivation to design ontologies based on patterns is because patterns can help in codifying knowledge of the domain, which in this case is instructional design and ontologies help in representing this knowledge in a concrete way and make the knowledge amenable for machine-processing which is not possible with patterns alone (Chimalakonda, 2017). Furthermore, our goal to support scale and variety, which could be supported by patterns (Chimalakonda, 2017).

Diversified needs emerging from different domains gave raise to a spectrum of ontology kinds (Uschold \& Gruninger, 2004; Giunchiglia \& Zaihrayeu, 2009) as shown in Fig. 1. These kinds of ontologies vary based on the degree of specification detail, scope, formalism and expressiveness power as we move from one end to the other end of the spectrum (Wong et al., 2012). In essence, there are informal or lightweight ontologies on one end, primarily geared towards some sort of communication and on the other end, formal ontologies help in automated reasoning of knowledge (Giunchiglia \& Zaihrayeu, 2009). This paper falls in the middle and mostly uses OWL/XML Schemas to 


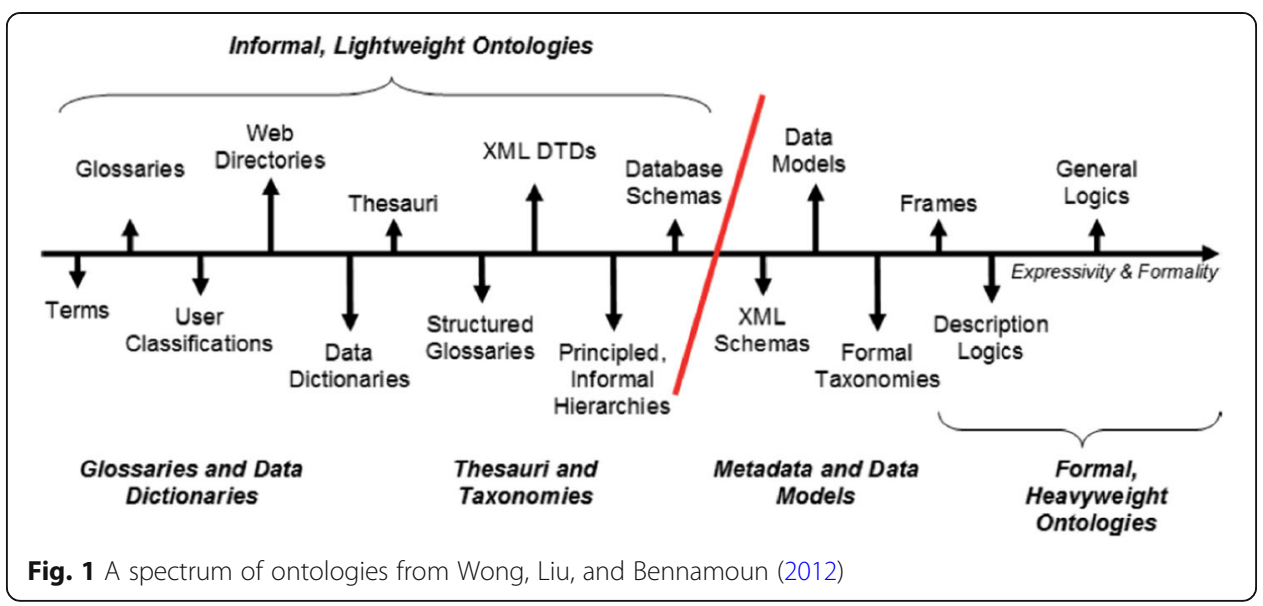

address the primary needs of communication and automation. They also provide a mechanism to use instructional design as a basis throughout the design of educational technologies.

\section{Ontologies for adult literacy instructional design}

In this section, we discuss our notion of ontology for adult literacy instructional design in relation to the existing literature. The term ontology is used in a variety of ways in the literature (Uschold \& Gruninger, 2004; Wong et al., 2012). A commonly used definition of ontology in computer science comes from Gruber (1993), where he defines an ontology as "a formal, explicit specification of a shared conceptualization".

To the best of our knowledge, we could not find any ontologies that are even remotely connected to adult literacy in India. But we discuss a few related ontologies from the literature. An ontology for literacy was proposed for intelligent tutoring systems in 1999 (Carvalho \& Pain, 1999). We then looked into some upper ontologies, we found a curriculum ontology devised by BBC for the national curricula on UK focusing on three topics [Algebra, Geometry, Formula], level [KS1, KS2, KS3, GCSE] and different fields of study [Maths, English, Science] (BBC, 2020). A comprehensive ontology that models several learning theories is presented in (Bourdeau et al,, 2007) where the idea is to have solid pedagogical basis for intelligent tutoring systems. Heiyanthuduwage, Schwitter, and Orgun (2016) have analyzed 14 ontologies developed by different institutions for learning design and proposed an OWL-2 learners profile. Mizoguchi, Vanwelkenhuysen, and Ikeda (1995) proposed a task ontology to facilitate reuse of problem solving knowledge. We came across several ontologies focusing on a particular kind of instructional design; for example, a mobile learning ontology was designed for abductive science inquiry style of instruction (Ahmed \& Parsons, 2013). An ontology for learning scenarios based on collaborative learning theories (Isotani et al., 2013), gamification (Challco et al., 2020) and on subject matter such as word problems in mathematics (Lalingkar, Ramanathan, \& Ramani, 2015), software engineering body of knowledge (Abran et al., 2006), systems engineering (Yang, Cormican, \& Yu, 2020) were proposed. Recently, an ontology was proposed for nutrition and food literacy skills (Mitsis, Zarkogianni, Bountouni, Athanasiou, \& Nikita, 2019). 
In addition to these, ontologies were developed for learning content (Verbert, Jovanovic, Duval, Gasevic, \& Meire, 2006), learning design based on IMS-LD standard (Amorim et al., 2006), learning styles (Labib, Canós, \& Penadés, 2017), a context ontology for bridging the gap between learning content and learning design (Jovanović, Knight, Gašević, \& Richards, 2006). There were ontologies to represent learning object repositories (Wang \& Koohang, 2009) and learning design repositories (Paquette, 2014) to facilitate search and retrieval of learning resources on the web. However, none of these ontologies cater to the need of scale and variety inherent in the problem domain and are not driven by patterns motivating the need for our research and as such no ontologies were available for adult literacy in India.

Technology-enhanced learning has received significant attention from researchers and practitioners to improve quality of teaching and learning (Dunn \& Kennedy, 2019; Serrano, Dea-Ayuela, Gonzalez-Burgos, Serrano-Gil, \& Lalatsa, 2019; Shen \& Ho, 2020). IntelLEO is one of the earlier projects that uses a set of ontologies to foster integration of learning across organizations (Stokić et al., 2008). STELLAR is another large-scale effort that has driven research and practice in multiple interdisciplinary areas of TEL (Gillet, Scott, \& Sutherland, 2009). There were several EU-funded projects in building large scale infrastructure for managing the entire life cycle of learning objects and open educational resources. ${ }^{4}$ Nikolas, Sotiriou, Zervas, and Sampson (2014) have reviewed existing literature and presented a digital infrastructure that addresses several requirements for managing learning repositories. Learn2Analyze (L2A) is another initiative that aims at educating teachers on using analytics to improve teaching and learning. ${ }^{5}$ Nouira, Cheniti-Belcadhi, and Braham (2019) have proposed an ontology-based framework focusing on assessment analytics for massive learning. However, none of these initiatives focus on adult literacy, which we aim to do in this paper.

In the next section, we will briefly discuss the approach for development of ontologies.

\section{IDont - an ontology based framework for modeling instructional design Ontology development methodology}

There are several approaches in the literature that support ontology development (FernándezLópez \& Gómez-Pérez, 2002; Gomez-Perez, Fernández-López, \& Corcho, 2006; Mizoguchi \& Bourdeau, 2016). In their Ontology Development 101, Noy, McGuinness, et al. (2001) proposed an iterative approach for building ontologies consisting of several activities that need not be sequential (i) determine scope (ii) consider reuse (iii) enumerate terms (iv) define classes (iv) define properties (v) define constraints (vi) create instances. An important conclusion from their work is "there is no single correct ontology for any domain. Ontology design is a creative process and no two ontologies designed by different people would be the same". Based on the domain and our requirements (Guarino, 1998), we confine ourselves to the descriptive use of ontologies and use OWL/XML for representing ontologies in this paper.

We see three major directions for developing ontologies from a synthesis of the literature (i) manually by expert(s) for specific purposes following a varied set of processes from lightweight to a rigorous standard process (ii) semi-automatic way of developing ontologies, where a part of the ontology is developed manually and a part is automatically retrieved using text mining, natural language processing and other techniques (iii) fully automatic development, where the ontologies are derived using ontology learning approaches.

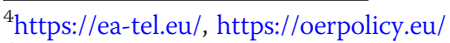

${ }^{5}$ https://learn2analyse.eu/
} 
Based on (i) and (ii), we follow a simple process for developing ontologies in this paper. The first step in the process is to determine the requirements from the ontology, which is driven by the set of $e$ Learning Systems to be developed in our case. The next step is to figure out the scope of the ontology drawing a boundary for what is within and outside the scope. Once the scope is defined, the next step is to identify any existing ontologies that can be used for creating the ontology. We discuss the ontologies we adapted from existing literature in the next section. Once the suitable sources for ontologies are defined, the next step is to use a standard approach to identify the concepts, relationships between the concepts, define properties, constraints and instances using an appropriate representation language like OWL/RDF. An important distinction of this process from the standard ontology development methodologies is the use of patterns as one of the critical sources for building ontologies.

The patterns themselves are discovered after extensive discussions with domain experts; rigorous analysis of literature and analyzing existing applications that are built in the domain. We have extensively discussed with domain experts from $\mathrm{Na}$ tional Literacy Mission Authority (NLMA) ${ }^{6}$; analyzed literature on adult literacy and instructional design as a source for our patterns. We also analyzed several $e$ Learning Systems developed by TCS for 9 Indian languages before creating the patterns. We use these patterns as one of the primary source for creating the ontologies. We also consider other literature from the instructional design space as input to our ontologies. The output of this entire exercise of conceptualization and implementation is a set of ontologies, which are used as a basis for creation of eLearning Systems. Figure 2 shows a part of evolution of scope for our instructional design ontology framework.

For example, we use ContentPattern as the basis for ContentOntology (An ontology for modeling instructional material section). The ContentPattern models instructional material as a gradual knowledge progression of (facts $\rightarrow$ cases $\rightarrow$ rules $\rightarrow$ models $\rightarrow$ theories) and an example instantiation for adult literacy in Hindi language is: ContentPattern ${ }^{1}$ :syllables (म, क, न) $\rightarrow$ words (नम, मकान) $\rightarrow$ rules (क +ा = का) $\rightarrow$ phonetic model $\rightarrow$ eclectic method. Here, each of the aspects of facts, cases, rules, models and theories provide variation points such that they can be varied for different contexts. For instance, the above example with variations for Telugu language can be syllables $(మ, న, \infty) \rightarrow$ words (మనం, మరిది) $\rightarrow$ rules $(\checkmark+\infty=న ం)$. This pattern is driven by goals, which are also modeled using a GoalPattern based on Bloom's taxonomy: Capability (remember, understand, apply, analyze, evaluate, create), Condition, Criteria. An instantiation is GoalPattern ${ }^{1}$ : The learner should be able to remember syllables (म, क, न) and recognize them from a newspaper in less than a minute. Figure 3 shows examples of facts, cases for Telugu language based on ContentPattern. A detailed discussion of this patterns and patterns based approach is presented in Chimalakonda (2017).

\section{IDont framework}

There are tremendous efforts to model a variety of instructional designs in the space of educational technologies (Bohl, Scheuhase, Sengler, \& Winand, 2002;

${ }^{6}$ NLMA is an autonomous wing of Ministry of Human Resource Development, Government of India, at national level for Adult Education Programmes and institutions, http://mhrd.gov.in/nlma 


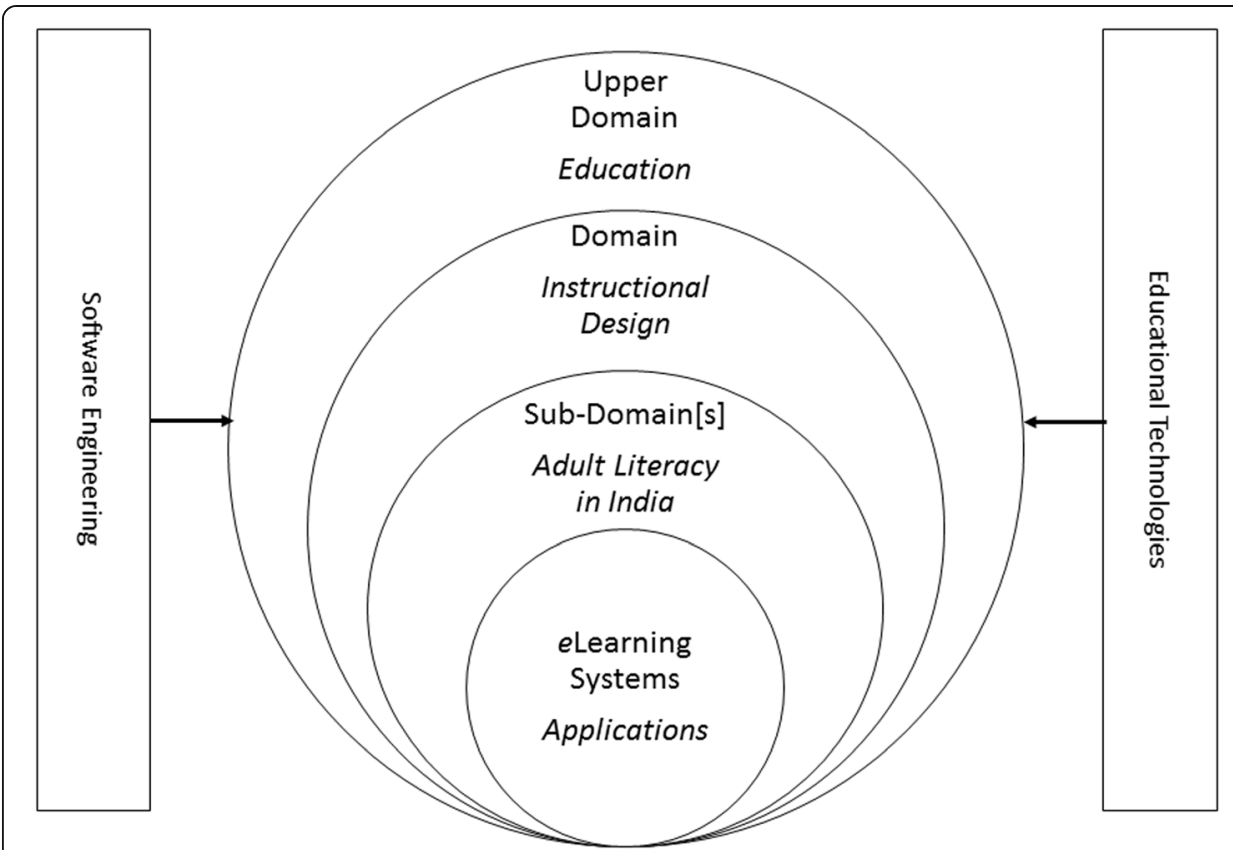

Fig. 2 Scope of Ontologies in this paper

Neven \& Duval, 2002; Rodríguez-Artacho \& Maillo, 2004; Koper, 2005; Sicilia, Lytras, Sánchez-Alonso, García-Barriocanal, \& Zapata-Ros, 2011; Burgos, 2015; Piskurich, 2015; Larson \& Lockee, 2019), platforms and tools (Botturi et al., 2008; Lachheb \& Boling, 2018). However, despite significant progress, most of the promises in educational technologies seem to be unfulfilled (Toyama, 2011; HernándezLeo, Asensio-Pérez, Derntl, Prieto, \& Chacón, 2014; Cuban \& Jandrić, 2015; Selwyn, 2020). We learn from these experiences and propose a framework for modeling instructional design using ontologies based on patterns. The proposed framework does not aim to provide an end-to-end automation solution but rather proposes placeholders for different components of instructional design. The design principles for IDont are as follows:

- Simplicity and Separation of concerns approach

- Leverage and Reuse existing ontologies

- Extensibility and Customization

- Iterative and Collaborative approach

- Internationalization of ontologies

The core premise of this framework is to systematically model instructional design using different aspects such as context, goals, process, content, evaluation, environment. We distinguish between two kinds of instructional design knowledge, one is at a conceptual level that maps with existing learning methodologies and the other is at a technical level to facilitate semi-automatic development of $e$ Learning Systems. As such, the core idea of IDont is not to define complete ontologies but to point to several possible modular ontologies that are placeholders for systematic modeling of instructional design. As such, most of the aspects of IDont are optional and can be configured based on specific purposes and learning 


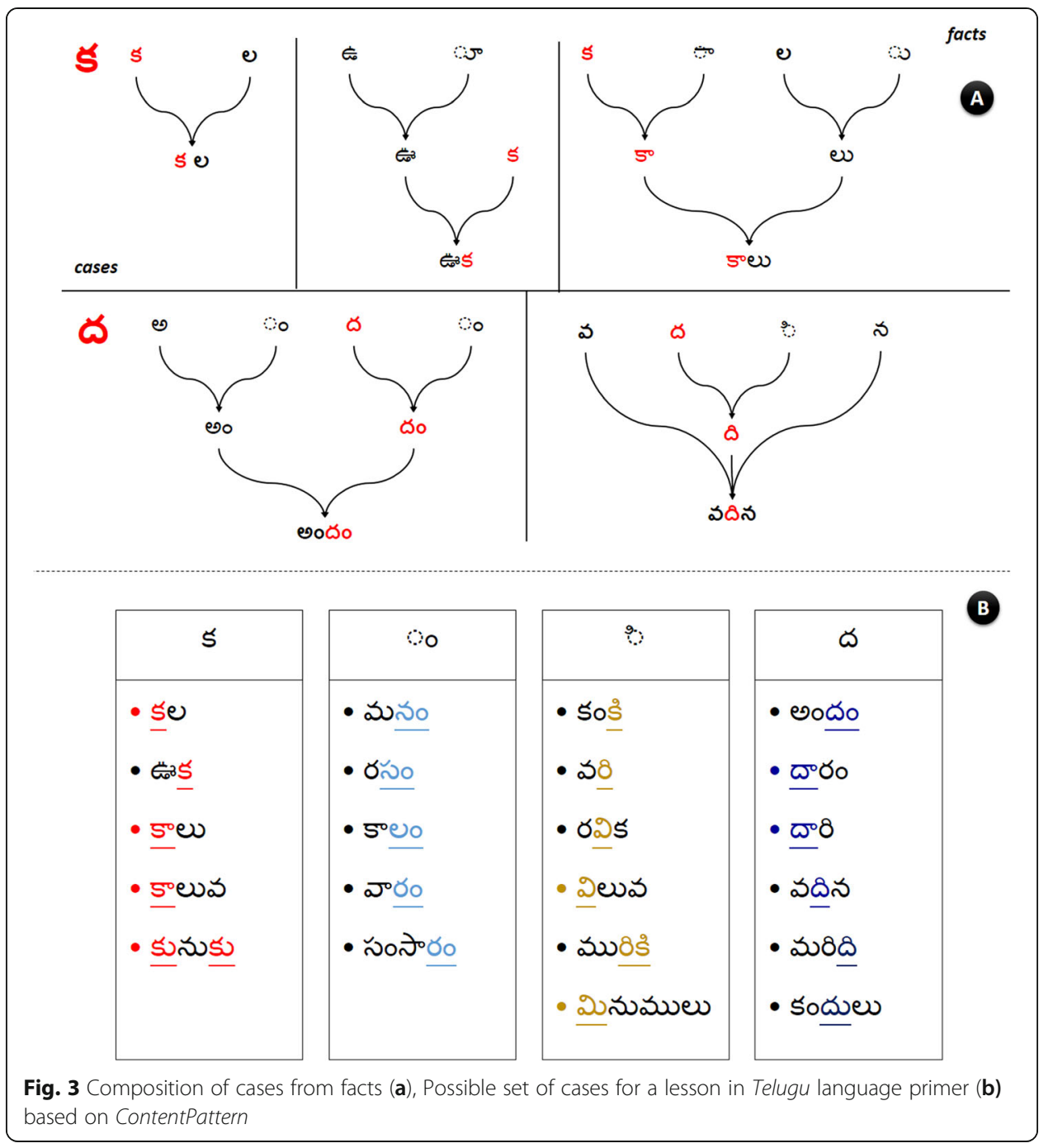

situations. Figure 4 shows an overview of the IDont framework. The key inputs come from a set of instructional design requirements that drive selection of appropriate instructional design models, which are captured as patterns in our approach. We do not specify the exact ontologies for instructional design but have placeholders for different aspects. With the advent of several ontology repositories, an instructional designer or ontology engineer can either extract the required ontologies for specific instructional design model from existing literature or create a new one. This generic instructional design stitched from existing or new ontologies can be customized with domain ontologies and can be further realized by specific instances like ID1, ID2 ... IDn.

Figure 5 presents an overview of the instantiation of IDont framework for adult literacy. Even though we show several ontologies in the diagram, we focus our discussion on goals, process and content ontologies. We briefly explain the important ontologies of our framework as follows:

A. ContextOntology - Context plays a significant role in IDont as it allows for modeling of various aspects related to a particular learning situation. The notion of learning context was proposed in LOCO ontology to bridge the gap between 


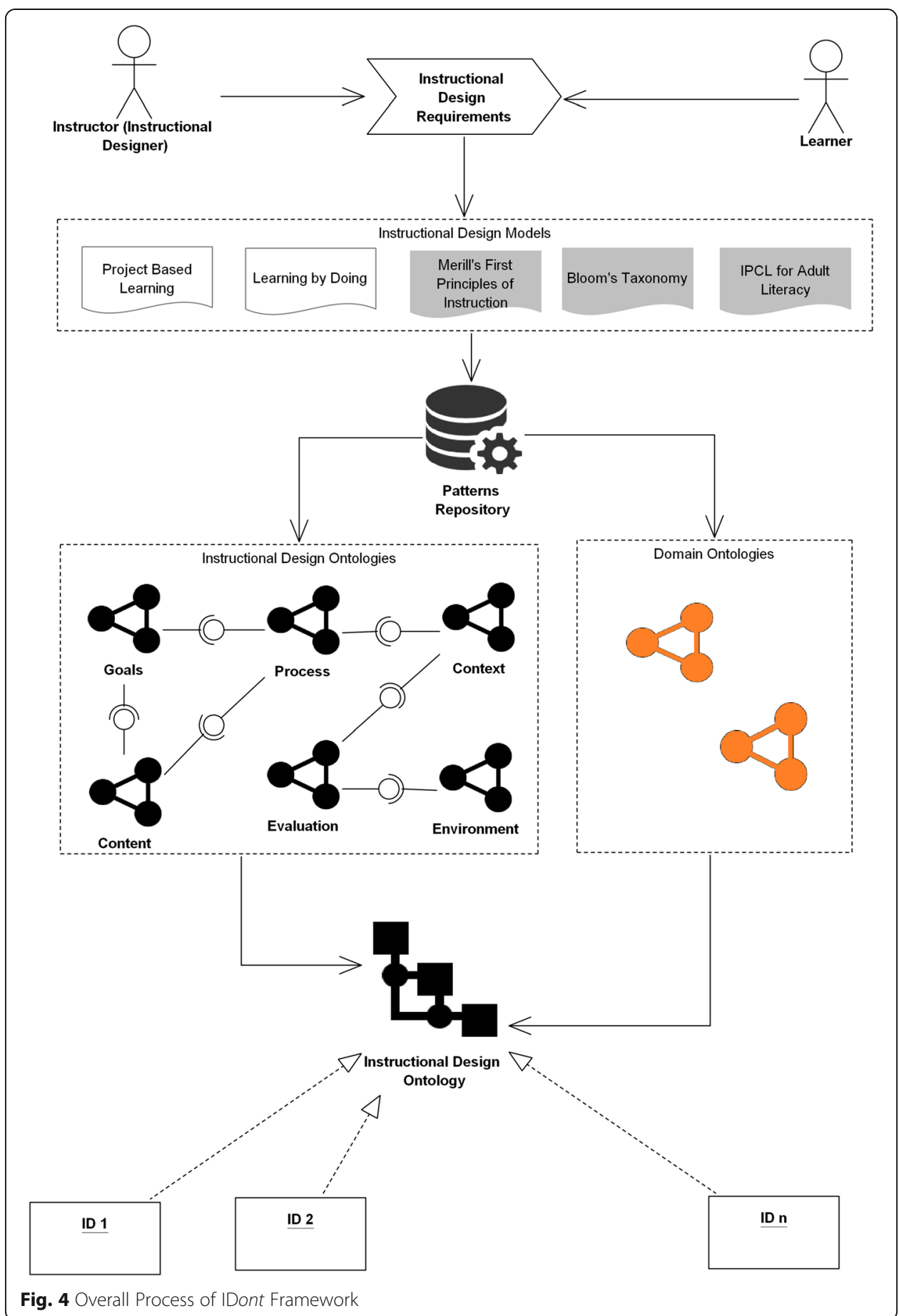

learning design and content consisting of domain specific information (Knight et al., 2006). However, in this framework, we articulate context in a broader view that encompasses several pointers to all other ontologies. This is a meta-ontology that essentially captures the basic information related to all other aspects of instructional design such that each of these aspects can be potentially (re)used. As shown in Fig. 5, ContextOntology has metadata associated with it along with context information related to various aspects of instructional design. ContextOntology 


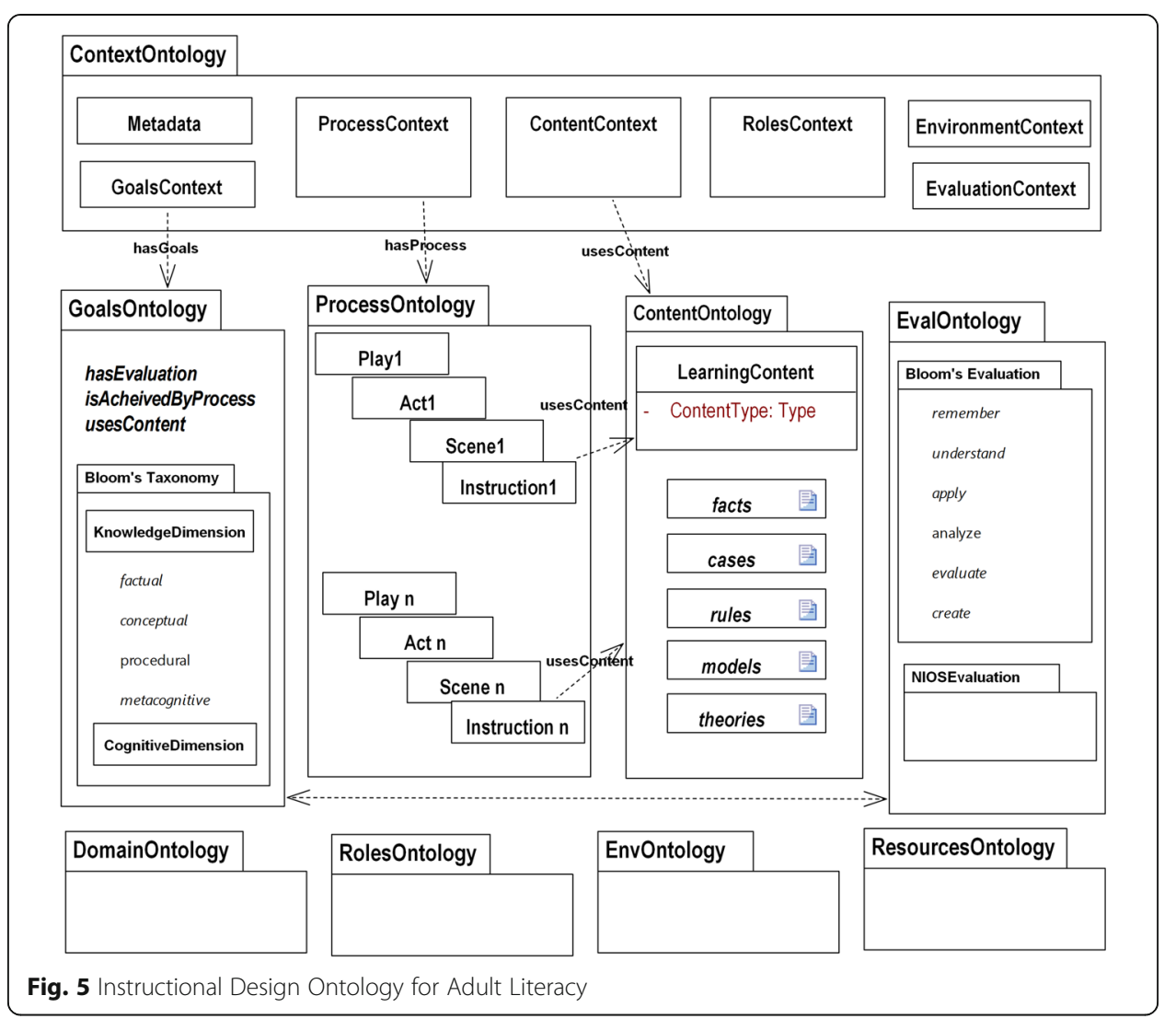

specifies how a ProcessContext achieves goals using ContentContext delivered through EnvrionmentContext following EvaluationContext and performed by RolesContext.

B. GoalsOntology - This ontology formalizes the notion of goals (which can be instructional goals, learning goals or even learning outcomes). The details of how it is defined are left to the specific instance. Some properties associated with goals are hasName, hasPriority, hasPrerequisites, hasEvaluation, isAchievedByProcess. The GoalsOntology points to the process through which these goals will be achieved, target competencies, the instructional material that is required and the evaluation to be performed. Consider the scenario of creating goals for K12 students, and goals are prescribed by education boards. Teachers can potentially reuse these goals if captured in the form of GoalsOntology. As the evaluation related to these goals is separately captured, it can be reused as well. We prescribe to the idea of goal-driven instruction as part of our framework irrespective of instructional design models. We detail GoalsOntology in the latter part of this paper in An ontology for modeling goals section.

C. ProcessOntology - The crux of IDont framework is the ProcessOntology that captures the instructional design process, and relates to all other ontologies and practically executes the process. In the literature, Learning Design is discussed heavily, in particular IMS Learning Design (Consortium et al., 2003) and received criticism as well (Burgos, 2015). Amorim et al. (2006) have presented ontologies for modeling learning design. Based on our prior experience with adult literacy 
instructional design, IPCL and our future goal to introduce reasoning into educational technologies, we proposed the ProcessPattern - pasi (play, act, scene and instruction) (Chimalakonda \& Nori, 2014). Each lesson is organized as a hierarchy of pasi with instructions where concrete activities are performed based on Merill's principles of instruction in this particular instance. This instruction actually points to ContentOntology and associates required content for the respective instruction. This nomenclature allows us to systematically capture the knowledge of instructional design process and potentially reduce technological effort. This hierarchy has similarities to IMS LD but has variations to align with patterns for adult literacy instruction. We will present the ProcessOntology in An ontology for modeling instructional processes section.

D. ContentOntology - This ontology allows for modeling of instructional material in a particular learning situation. There is extensive research on ontologies for learning objects and we use the ALOCoM ontology (Verbert et al., 2006) as base for content aspect of our framework. However, for adult literacy instructional design, we have used fcrmt (facts, cases, rules, models, and theories) structure (Chimalakonda, 2017) as discussed in An ontology for modeling instructional material section. So the ContentType of ALOCoM also includes fcrmt to support reasoning. The ContentOntology is closely associated with other ontologies and strongly with the ProcessOntology.

E. EvaluationOntology - What if the most common evaluations of instructional design are captured and an instructor can customize them based on his or her requirements? The main intent of this ontology is to capture evaluations as independent knowledge and link them with goals through ContextOntology. This separation makes it easier to perform different kinds of evaluations for the same set of goals. This ontology captures the details of evaluation and has a direct relationship with GoalsOntology which is in turn connected with ProcessOntology.

F. DomainOntology - This ontology mainly articulates and customizes key aspects of instructional design with respect to a specific domain and provides a domain-specific version of the ontology. In particular, the various sub-ontologies and properties of these ontologies will have detailed associations when mapped to a specific domain. For example, the ContentOntology has strong co-relation and mapping with content in the domain.

There can be several other ontologies like RolesOntology capturing roles and their responsibilities, ActivitiesOntology for activities, WorkflowOntology to model the tedious workflows, FeedbackOntology for continuous feedback, OrganizationOntology focusing on organizational characteristics, ResourcesOntology, having pointers to resources such as text, audio, video and so on. In our analysis of instructional design literature, we strongly see that it is virtually impossible to capture all kinds of instructional design models and any attempt towards it turns to be futile. However, the main intent of our framework is to use a separation of concerns approach to systematically capture various aspects of instructional design through ontologies.

We discuss the specific ontologies that are developed to demonstrate IDont framework for adult literacy case study, as the proposed framework does not propose a fixed number of ontologies or properties. Our attempt is not to present complete ontologies 
but to design educational technologies in sync with instructional designs and for scale and variety. We also include several entities in the ontologies for future use rather than just current needs. We discuss three core ontologies of our framework through adult literacy case study in the next sections.

\section{An ontology for modeling goals}

The primary goal of any instructional design is to find ways to support learners in achieving their learning goals (Ram \& Leake, 1995). Based on the pattern discussed for goals in (Chimalakonda, 2017), we present an ontology for representing instructional goals in this section based on revised Bloom's taxonomy (Anderson et al., 2001). Figure 6 shows a part of GoalsOntology $y^{7}$ developed using protégé ${ }^{8}$ tool from Stanford. The priority of the goal is described using GoalPriority, progress through GoalProgress, deadline through the property goalDeadline. An important sub-class is to classify the goal according to a tax-onomy. The class GoalClassification is further divided into two classes BloomTaxonomy and $A B C D$.

The BloomTaxonomy is further divided into KnowledgeDimension and CognitiveProcessDimension as per revised Bloom's taxonomy. The knowledge can be classified as FacutalKnowledge, ConceptualKnowledge, ProceduralKnowledge and MetaCognitiveLevelKnowledge with increasing levels of higher order levels of thinking. This is in sync with the ContentOntology that will be discussed in An ontology for modeling instructional material section. The CognitiveProcessDimension is the most commonly used way to classify goals as per Bloom's taxonomy. It has six levels Remember, Understand, Apply, Analyze, Evaluate, Create and each of them have several verbs specifying the activities.

Several object properties are shown in Fig. 6 connecting different concepts in the ontology. Priority of the goal can be captured using goalPriorityLevel, competency through goalCompetencyLevel and goalKnowledgeLevel can have a range of values from the KnowledgeDimension and maps to the fcrmt pattern. Every goal should have a goalDeadline and its progress is monitered through goalProgress. A goal also has hasPrerequisites, previousGoal and nextGoal. This ontology is connected to ProcessOntology through isAchievedByProcess, ContentOntology via usesContent, EvaluationOntology through ha-sEvaluation and runsInEnvironment.

In addition, there are several data properties that are associated with the ontology. For example, goalDeadline stores the deadline as dateTime. The goal itself can be described using goalText, goallmage, goalAudio, goalVideo, goalMetadata. These data properties store specific information that can be later used for (semi-)automatic generation. GoalGranularity is another critical class that is specific to our instructional design as we have a goals hierarchy akin to play, act, scene, instruction pattern. In addition to the standard concepts, the ontology also has concepts for GoalPattern consisting of properties shown in Fig. 6. For example, SourceOfPattern is a data property that specifies the source of the patterns, Trade-Offs specifies the issues that might occur using this pattern. In our case, we realized that if specifying goals requires so much of effort, the entire exercise will be a burden for teachers and instructional designers making it a futile effort in the end. Hence, we have minimal mandatory properties with scope for using extended properties only if required.

\footnotetext{
${ }^{7} \mathrm{~A}$ detailed overview of this ontology is available at https://goo.gl/wdRU5b.

${ }^{8}$ http://protege.stanford.edu/

${ }^{9} \mathrm{~A}$ detailed overview of this ontology is provided in https://goo.gl/5A937v.
} 


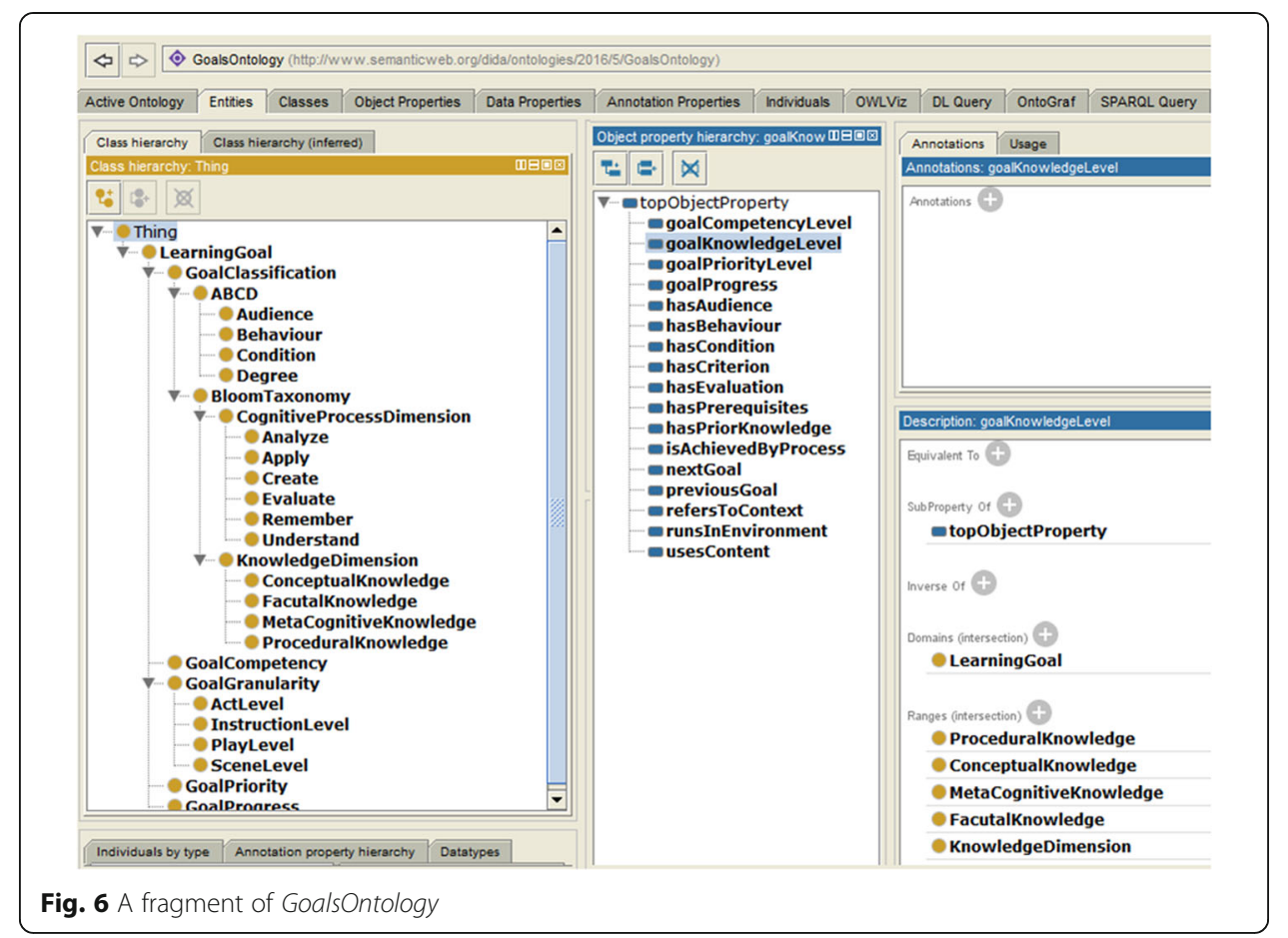

\section{An ontology for modeling instructional processes}

The ProcessOntology ${ }^{9}$ is a core ontology for specifying instructional process and is closely associated with several other ontologies. As shown in Fig. 7, the ontology is divided into three conceptual sections at a higher level (i) learning, focusing on concepts that map to the underlying learning methodologies (ii) metadata consists of information about the process in general (iii) user interface to declaratively specify a few aspects of the

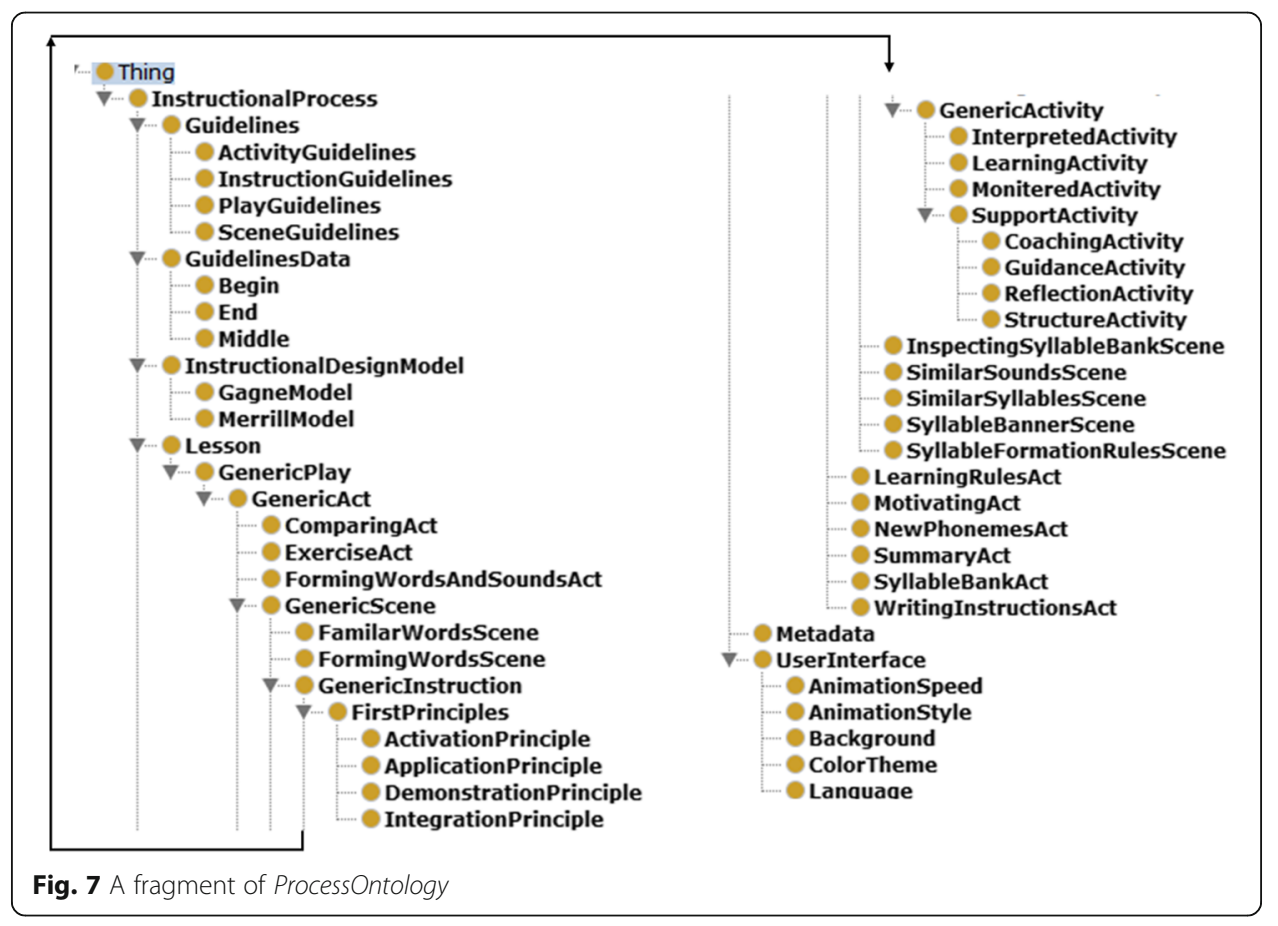


eLearning System. The ProcessOntology is based on ProcessPattern (Chimalakonda, 2017; Chimalakonda \& Nori, 2014) and its primary purpose is to achieve goals specified in the GoalsOntology and is connected through hasAssociatedGoal property. These goals have to be achieved using content specified via ContentOntology connected through the object property usesContent. Similarly, usesEvaluation, performedbyRole, runsInEnvironment connect this ontology to EvaluationOntology, RolesOntology and EnvironmentOntology respectively. This ontology has several data properties such as title, description, metadata, noOfPlays, noOfScenes, noOfInstructions. One important property is hasTimeLimit that specifies the time limit for an activity, instruction, scene, act, play. Guidelines is an important concept that we use for giving instructions to learners during their interaction with the eLearning System at different levels of granularity specified using PlayGuidelines, ActGuidelines, SceneGuidelines, InstructionGuidelines, ActivityGuidelines. For example, a guideline from a teacher might be "Everybody look at the screen and observe how the two syllables are combined together to form a new word". Separating this in-formation provides the flexibility to change guidelines. This can be specifically used to change medium of instruction in an eLearning System. For example, a language like Hindi can be taught using Telugu as medium of instruction by changing the guidelines in the entire system.

The base InstructionalDesignModel can be specified as MerrillModel or any other instructional design model from the literature. We use MerrillModel as it is based on first principles of instruction distilled from several instructional designs (Merrill, 2012). Then each lesson is modeled using a set of plays (GenericPlay) that are divided into acts (GenericAct), which are further divided into scenes (GenericScene) and instructions (GenericInstruction). We have identified different kinds of acts for adult literacy instruction which include MotivatingAct, NewPhonemesAct, FormingWordsAndSoundsAct, SyllableBankAct, ComparingAct, LearningRulesAct, WritingInstructionsAct, ExerciseAct, SummaryAct. We inferred these acts from adult literacy eLearning Systems that are tested on the field. There are different kinds of scenes SimilarSoundsScene, SimilarSyllablesScene, InspectingSyllableBankScene, SyllableFormationRulesScene, FamilarWordsScene, SyllableBannerScene, FormingWordsScene under each act. Each scene further has instructions which have direct activities for facilitating learning. Each instruction follows one or more principles and can have one or more activities. We specify Merrill's first principles of instruction using FirstPrinciples that is further divided into IntegrationPrinciple, ActivationPrinciple, DemonstrationPrinciple, ApplicationPrinciple, DemonstrationPrinciple. Activity is one of the most commonly used concept in the space of instructional design and we model that using GenericActivity. We incorporate two kinds of activities from the literature LearningActivity and SupportActivity. But we also model four kinds of additional activities StructureActivity, GuidanceActivity, CoachingActivity and ReflectionActivity to accommodate Merrill's inner circle of structure-guidancecoaching-reflection. Modeling these activities as concepts allows us to change these activities based on learner styles or instruction styles. In addition, InterpretedActivity and MoniteredActivity help from evaluation perspective.

The current ontology also has basic concepts for UserInterface such as AnimationStyle, ColorTheme, AnimationSpeed, Language, Background. The instances of these 
concepts will help in configuring the user interface of $e$ Learning Systems for adult literacy based on specific requirements.

One principle behind this ontology is not to use all the classes and properties but to further filter this ontology to the specific needs and use only a fragment of the ontology in order to reduce the burden on the teachers and instructional designers. For example, if a course has 1000 instructions in total, then specifying principles for all of these instructions might be a burden and an alternative could be to make this property optional at instructional level but mandatory at a scene or act or play level.

\section{An ontology for modeling instructional material}

The ContentOntology ${ }^{10}$ ontology is primarily derived from existing literature on learning objects and specifically the ALOCoM ontology (Verbert et al., 2004) along with the ContentPattern elaborated in (Chimalakonda, 2017). As shown in Fig. 8, this ontology includes four core concepts ContentType, ContentFragment, ContentObject, LearningObject. The raw data in the form of text, audio, animation, video are concepts in ContentFragment and ContentObject is an aggregation of several content fragments. This ontology is further refined in terms of ContentType, which includes Facts, Cases, Rules, Models, Theories, which form the CoreType. In ExtendedType, there are further concepts derived from the literature (Verbert et al., 2004). Essentially, they capture learning objects at a higher level of abstraction. Another important concept is LearningObject which has the sub concepts of PlayObject, ActObject, SceneObject, InstructionObject. These concepts are connected to respective elements in ProcessOntology.

There are other ontologies for specifying Roles, Evaluation, Environment that are part of instructional design ontology but defining those ontologies is beyond the scope of this work. The RolesOntology is an interesting one with roles such as Teacher, Mentor, TeachingAssistant, Coach and so on and can be mapped to different kinds of activities in the ProcessOntology. As an example, learning styles and teaching styles may be used in the role of learner and teacher in RolesOntology. In the next section, we will discuss the evaluation of our approach.

\section{Evaluation}

There are several ways of evaluating ontologies in the literature such as gold standardbased, corpus-based, task-based and criteria based (Brank, Grobelnik, \& Mladenic, 2005; Cristani \& Cuel, 2005; Sfar, Chaibi, Bouzeghoub, \& Ghezala, 2016). However, these approaches are for evaluating ontologies, and not directly for an ontology framework, which is the case in this paper. Our evaluation strategy is three-fold:

- Instantiation of the IDont framework for adult literacy case study - As a first step, we first selected the appropriate ontologies that fit the adult literacy case study, which include goals, process and content and appropriate properties in each of these ontologies that are relevant to support variations in instructional designs for adult literacy. Figure 9 shows a fragment of instantation of IDont framework for adult literacy. Lines 3 to 20 correspond to goals, which show that Bloom's revised taxonomy is selected in this instructional design specification and lines 41 to 63

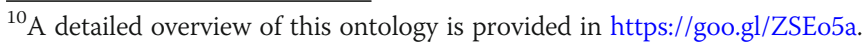




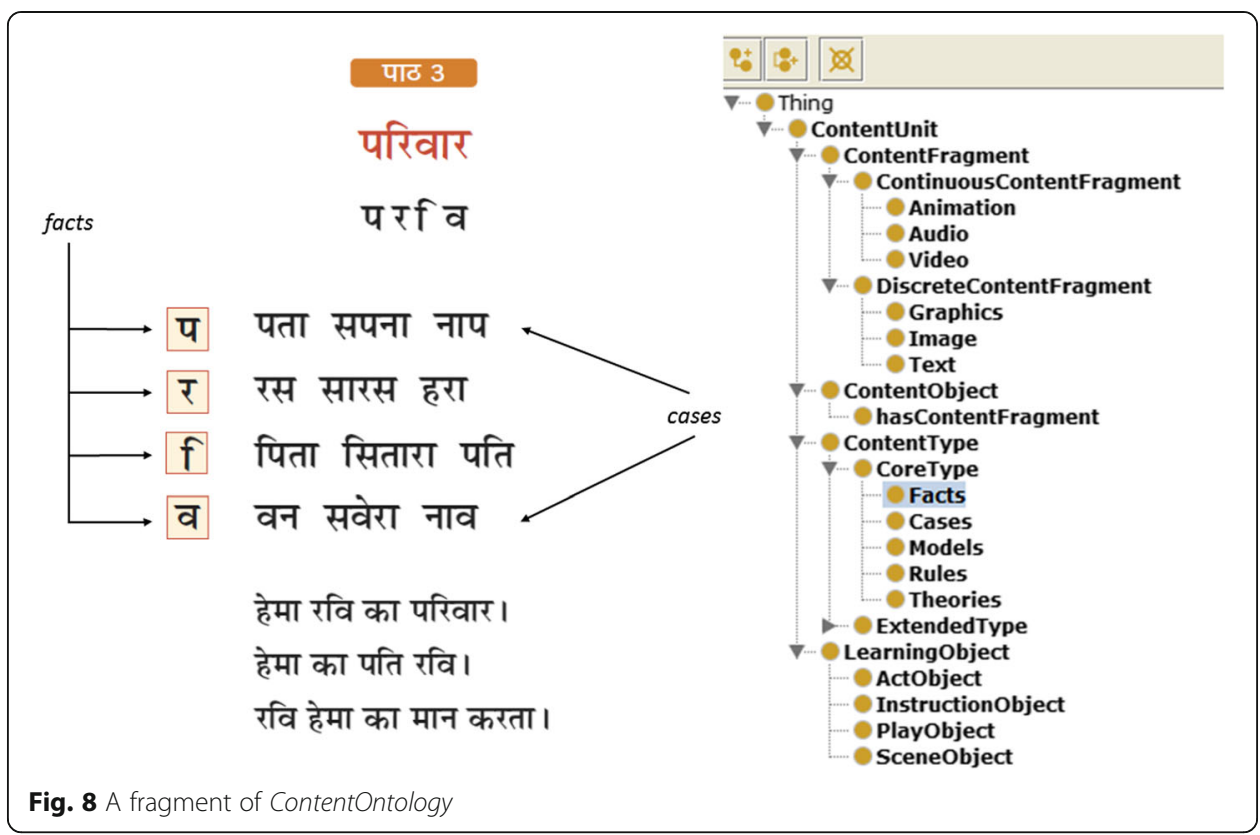

show how the process is modeled as plays, acts and scenes. This instantiation is essentially derived based on the ontology in Discussion \& conclusions section. A more specific example from Telugu language shown in Fig. 10 shows how goals, facts, cases are integrated in acts and scenes. Variations in each of these properties will lead to variations in different aspects of instructional design.

- We have created a software platform based on the IDont framework for modeling variations in instructional design and demonstrated the platform to create multiple eLearning Systems. We have demonstrated the application of our framework by automating the design and development of 9 eLearning Systems for adult literacy (Chimalakonda \& Nori, 2020). The details of the implementation are deeply rooted in software engineering research (Chimalakonda, 2017) and are beyond the scope of this paper.

- Acceptance by target user community, which is NLMA for adult literacy in India We have considered three sub-goals for evaluating the IDont framework within this mode. Our first goal is to see if adult literacy teachers with low-computer proficiency can use our platform to create instructional design variants. We have given training to teachers at State Resource Center, Telangana (Fig. 11(left)) who have used our platform and created an eLearning System that is hosted on Google Play Store ${ }^{11}$ in 2 weeks. Also, the eLearning System based on the framework along with variations is deployed on field to understand practical usage (Fig. 11(right)). Based on the positive feedback from initial field experiences, we have transferred the framework and platform to NLMA, which is the top-most authority for enforcing all SRCs across India for all official languages. Our platform is listed in the official websites of Department of Adult Education of Government of Telangana at http:// tslma.nic.in/ and State Resource Center, Government of Telangana at http://srctelangana.com/.

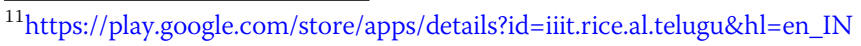




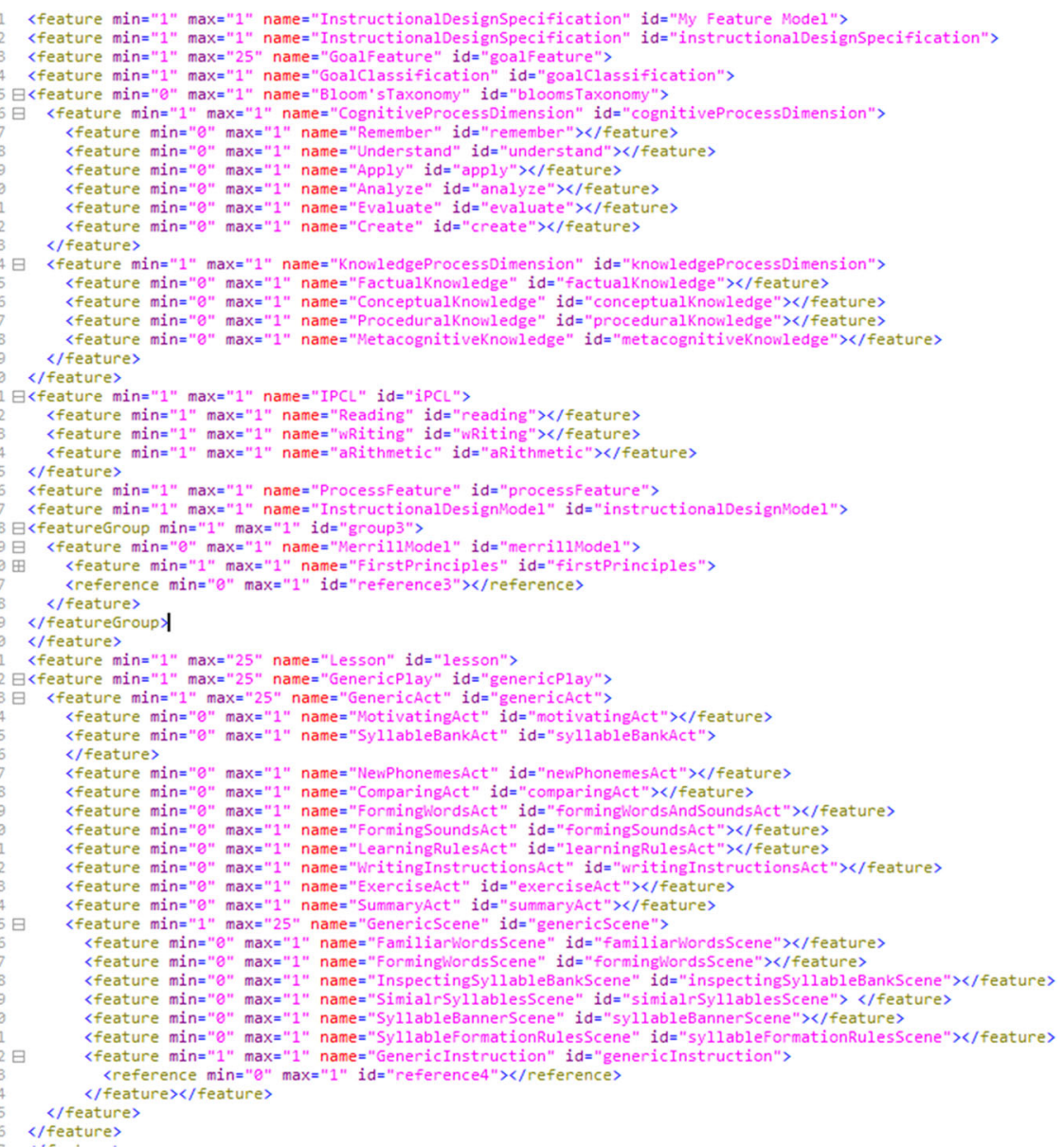

Fig. 9 Instantiation of IDont framework for adult literacy

In essence, we see that the proposed IDont framework has been validated through an implementation and on-field experiments. However, one major challenge with our evaluation is that the focus was primarily on how the proposed framework could be used for creating variations, rather than on whether the outcomes could yield better learning, making it a future work to do extensive field experiments from learning perspective.

\section{Discussion \& conclusions}

Instructional Design is one of the fundamental pillars of educational technologies and forms the basis for rest of the activities that drive effective instruction. In this paper, we motivated the need for modeling instructional design knowledge through ontologies to address scale and variety inherent in the domain. The key premise of the research in this paper is to systematically model different aspects of instructional design as modular ontologies such that these ontologies can be composed together to represent an instructional design and its variants. We specifically presented an ontology for modeling goals, an ontology for modeling instructional process and an ontology for modeling instructional material. We demonstrated each of these ontologies through adult literacy case study which requires hundreds of similar but distinct eLearning Systems to be developed. The 


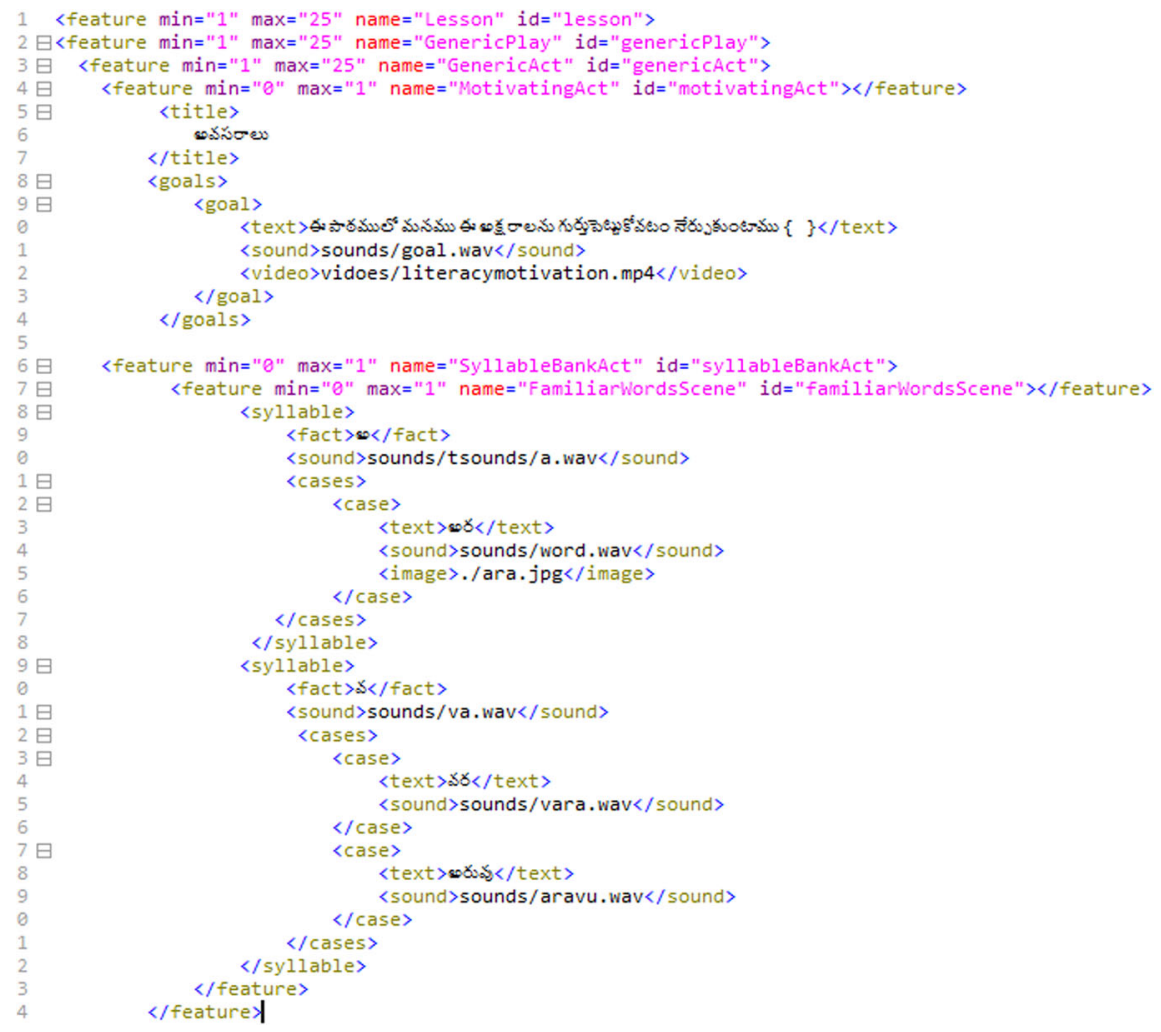

Fig. 10 A fragment of instance of MotivatingAct and SyllableBankAct for Telugu language

systems that are developed based on these ontologies are made available at http://rice.iiit. ac.in and transferred to NLMA.

The proposed ontology framework could add value on multiple fronts. The framework supports modeling a variety of instructional designs, which could be useful to adapt instructional designs for varying context, goals, process, content and so on. As the framework is based on modular ontologies, there is scope to support evolution of different aspects of instructional design. In addition, as the instructional design is available in a machine-processable format, tools could be leveraged to semi-automatically generate eLearning Systems. The framework also demonstrates the need to leverage and reuse existing onologies.
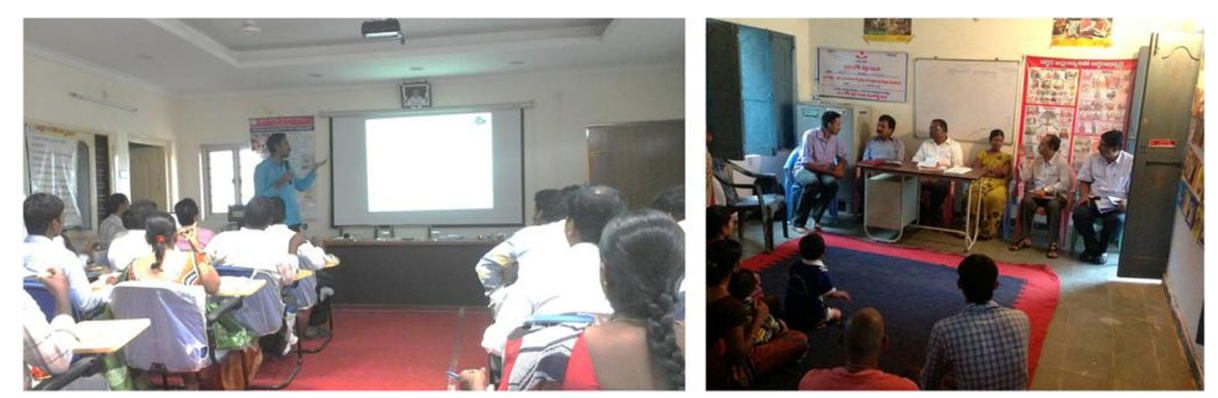

Fig. 11 Training for teachers on the usage of our platform [left] and field visit to Harshaguda Village, Hyderabad, India [right] 
The large scale nature of this research work has also provided several insights. It is critical to work with multiple stakeholders such as teachers, content providers, instructional designers and software engineers for successful implementation of a large scale infrastructure for educational technologies. The requirements from these various stakeholders have to be balanced, which otherwise could lead to a failure attempt. For example, technology experts often tend to ignore pedagogical aspects but have to be considered and on the other hand, some requirements of instructional designers might be technically not feasible. We also learnt the importance of understanding domain as a basis for design of educational technologies. Following an iterative approach is another key lesson for successful design and development of educational technologies.

On the other side, our approach has several limitations. Firstly, our approach is based on instructional design patterns, which are themselves fluid and can change over a period of time. As emphasized by Noy et al. (2001), "there is no single correct ontology for any domain. Ontology design is a creative process and no two ontologies designed by different people would be the same". This leads to a natural limitation of our approach as the proposed ontologies are only placeholders for different aspects of instructional design. We have extended and created several ontologies in our ontology framework. However, by definition, every domain can have several perspectives and hence several ontologies. In our ontology framework, we have introduced the notion of meta-ontologies for representing high level aspects of instructional design such as process and content. However, composition of other aspects of instructional design knowledge is not known to us. Our evaluation is limited as we tested our approach to show instructional design variants for adult literacy, which we consider as a large scale case study but may not be enough to generalize our approach.

With this context, the following are some potential directions for further research:

\section{Future work}

- Ontologies for domains beyond adult literacy. The first direction of future work is to apply the proposed framework for school education and skill education. We are currently working on adapting our ontologies to model skill curriculum, specifically focusing on vocational skills.

- Meta-ontologies that can connect multiple ontologies in varied contexts and multiple domains have to be created.

- Several ontologies other than goals, process, content that were introduced in the ontology framework have to be extended and created in full detail as a natural extension of the framework.

- With the availability of large volumes of data, the ontology framework should be extended to include learning analytics.

- The ontology framework could be extended to support personalized and adaptive educational technologies.

- Ontology-driven novel approaches to design of augmented and virtual reality based educational technologies could be experimented based on the framework.

${ }^{12}$ http://rice.iiit.ac.in 
- While we have built tools ${ }^{12}$ that help in development of systems, the platform generates eLearning Systems specific to adult literacy in India. There is a need for tools that can generate tools to generate tools.

- Creating collaborative, distributed and agile environments for domain and subject matter experts to create, share and disseminate their ontologies is a critical future step towards design of educational technologies for scale and variety.

\section{Acknowledgements}

We thank Tata Consultancy Services (TCS) for initial inputs, NLM for considering our work at national level, and Govt. of Telangana who are the early adoptors of the proposed work.

\section{Authors' contributions}

Dr. Sridhar Chimalakonda is the primary author of the work and has contributed to the idea, implementation and writing of the paper. Prof. Kesav V. Nori is the advisor and has guided the first author throughout the life cycle of the work as well as paper. The author(s) read and approved the final manuscript.

\section{Funding}

Not applicable.

\section{Availability of data and materials}

The work is available at http://rice.iiit.ac.in.

\section{Competing interests}

There are no competing interests.

\section{Author details}

${ }^{1}$ Department of Computer Science \& Engineering, IIT Tirupati, Tirupati, India. ${ }^{2}$ Software Engineering Research Center, IIIT Hyderabad, Hyderabad, India.

Received: 11 June 2020 Accepted: 31 August 2020

Published online: 09 October 2020

\section{References}

Abran, A., Cuadrado, J. J., García-Barriocanal, E., Mendes, O., Sánchez-Alonso, S., \& Sicilia, M. A. (2006). Engineering the ontology for the swebok: Issues and techniques. In Ontologies for software engineering and software technology, (pp. 103121). Springer, Berlin.

Ahmed, S., \& Parsons, D. (2013). Abductive science inquiry using mobile devices in the classroom. Computers \& Education, 63, $62-72$.

Amorim, R., Lama, M., Sánchez, E., Riera, A., \& Vila, X. (2006). A learning design ontology based on the ims specification. Journal of Eductational Technology and Society, 9, 38.

Anderson, L. W., Krathwohl, D. R., Airasian, P. W., Cruikshank, K. A., Mayer, R. E., Pintrich, P. R., .. Wittrock, M. C. (2001). A taxonomy for learning, teaching, and assessing: A revision of bloom's taxonomy of educational objectives, abridged edition. White Plains: Longman.

Aubin, G. P. C., \& Crevier, F. (1999). Misa, a knowledge-based method for the engineering of learning systems. Journal of Courseware Engineering, 2, 63-78.

Baral, C., \& De Giacomo, G. (2015). Knowledge representation and reasoning: What's hot. In AAAl, (pp. 4316-4317).

Barbagallo, A., \& Formica, A. (2017). Else: An ontology-based system integrating semantic search and e-learning technologies. Interactive Learning Environments, 25, 650-666.

BBC (2020). Curriculum ontology. URL: http://www.bbc.co.uk/ontologies/curriculum.

Bohl, O., Scheuhase, J., Sengler, R., \& Winand, U. (2002). The sharable content object reference model (scorm)-a critical review. In International conference on computers in education, 2002. Proceedings, (pp. 950-951). IEEE.

Botturi, L., Stubbs, S. T., \& Global, I (2008). Handbook of visual languages for instructional design: Theories and practices. Information Science Reference Hershey.

Bouihi, B., \& Bahaj, M. (2019). Ontology and rule-based recommender system for e-learning applications. International Journal of Emerging Technologies in Learning (iJET), 14, 4-13.

Bourdeau, J., Mizoguchi, R., Hayashi, Y., Psyche, V., \& Nkambou, R. (2007). When the domain of the ontology is education. In Proc. of I2LOR 07.

Brank, J., Grobelnik, M., \& Mladenic, D. (2005). A survey of ontology evaluation techniques. In Proceedings of the conference on data mining and data warehouses (SiKDD 2005), (pp. 166-170).

Buitrago, M., \& Chiappe, A. (2019). Representation of knowledge in digital educational environments: A systematic review of literature. Australasian Journal of Educational Technology, 35(4).

Burgos, D. (2015). A critical review of IMS learning design: recommendations for a revised version. In The art \& science of learning design, (pp. 137-153). Brill Sense.

Carvalho, M., \& Pain, H. (1999). An ontology for a literacy teaching its. In Al-ED99 workshop.

Challco, G. C., Bittencourt, I. I., \& Isotani, S. (2020). Can ontologies support the gamification of scripted collaborative learning sessions? In International conference on artificial intelligence in education, (pp. 79-91). Springer, Cham.

Chang, M., D'Aniello, G., Gaeta, M., Orciuoli, F., Sampson, D., \& Simonelli, C. (2020). Building ontology-driven tutoring models for intelligent tutoring systems using data mining. IEEE Access, 8, 48151-48162. 
Chimalakonda, S. (2017). A software engineering approach for design of educational technologies. Ph.D. Thesis, International Institute of Information Technology-Hyderabad.

Chimalakonda, S., \& Nori, K. V. (2013). Designing technology for 287 million learners. In 2013 IEEE $13^{\text {th }}$ International Conference on Advanced Learning Technologies (ICALT), (pp. 197-198). IEEE.

Chimalakonda, S., \& Nori, K. V. (2014). A patterns-based approach for modeling instructional design and tel systems. In 2014 IEEE 14th International Conference on Advanced Learning Technologies (ICALT), (pp. 54-56). IEEE.

Chimalakonda, S., \& Nori, K. V. (2018). A patterns based approach for design of educational technologies. arXiv preprint arXiv: 1802.02663 .

Chimalakonda, S., \& Nori, K. V. (2020). A family of software product lines in educational technologies. Computing, 1-28.

Consortium, I. G. L. et al. (2003). IMS learning design specification.

Cristani, M., \& Cuel, R. (2005). A survey on ontology creation methodologies. International Journal on Semantic Web and Information Systems (IJSWIS), 1, 49-69.

CSR, T. (2016). CSR case study, computer based functional literacy. URL: http://www.tcs.com.

Cuban, L., \& Jandrić, P. (2015). The dubious promise of educational technologies: Historical patterns and future challenges. ELearning and Digital Media, 12, 425-439.

Cubric, M., \& Tosic, M. (2020). Design and evaluation of an ontology-based tool for generating multiple-choice questions. Interactive Technology and Smart Education.

DAE (2003). Handbook for developing IPCL material. India: Directorate of Adult Education.

Dermeval, D., Leite, G., Almeida, J., Albuquerque, J., Bittencourt, I. I., Siqueira, S. W., ... Silva, A. P. D. (2017). An ontology-driven software product line architecture for developing gamified intelligent tutoring systems. International Journal of Knowledge and Learning, 12, 27-48.

Dermeval, D., Vilela, J., Bittencourt, I. I., Castro, J., Isotani, S., Brito, P., \& Silva, A. (2016). Applications of ontologies in requirements engineering: A systematic review of the literature. Requirements Engineering, 21(4), 405-437.

Deshpande, A., Desrochers, A., Ksoll, C., \& Shonchoy, A. S. (2017). The impact of a computer-based adult literacy program on literacy and numeracy: Evidence from India. World Development, 96, 451-473.

Devedzic, V. (1999). Ontologies: Borrowing from software patterns. Intelligence, 10, 14-24.

Dunn, T. J., \& Kennedy, M. (2019). Technology enhanced learning in higher education; motivations, engagement and academic achievement. Computers \& Education, 137, 104-113.

Fensel, D. (2001). Ontologies: Dynamic networks of formally represented meaning. Amsterdam: Vrije University.

Fernández-López, M., \& Gómez-Pérez, A. (2002). Overview and analysis of methodologies for building ontologies. The Knowledge Engineering Review, 17, 129-156.

George, G., \& Lal, A. M. (2019). Review of ontology-based recommender systems in e-learning. Computers \& Education, 142, 103642.

Gillet, D., Scott, P., \& Sutherland, R. (2009). Stellar european research network of excellence in technology enhanced learning.

Giunchiglia, F., \& Zaihrayeu, I. (2009). Lightweight ontologies. In Encyclopedia of database systems, (pp. 1613-1619). Springer.

Gomez-Perez, A., Fernández-López, M., \& Corcho, O. (2006). Ontological engineering: With examples from the areas of knowledge management, e-commerce and the semantic web. Springer Science \& Business Media.

Gruber, T. R. (1993). A translation approach to portable ontology specifications. Knowledge Acquisition, 5, 199-220.

Guarino, N. (1998). Formal ontology in information systems: Proceedings of the first international conference (FOIS'98), June 6-8, Trento, Italy volume 46. IOS Press.

Haendler, T., \& Neumann, G. (2019). Ontology-based analysis of game designs for software refactoring. In CSEDU (1), (pp. 2435).

Happel, H.-J., Maalej, W., \& Seedorf, S. (2010). Applications of ontologies in collaborative software development. In Collaborative software engineering, (pp. 109-129). Springer, Berlin.

Heiyanthuduwage, S. R., Schwitter, R., \& Orgun, M. A. (2016). Owl 2 learn profile: An ontology sublanguage for the learning domain. SpringerPlus, 5,1 .

Hernández-Leo, D., Asensio-Pérez, J. I., Derntl, M., Prieto, L. P., \& Chacón, J. (2014). Ilde: Community environment for conceptualizing, authoring and deploying learning activities. In European conference on technology enhanced learning, (pp. 490-493). Springer, Cham.

latrellis, O., Kameas, A., \& Fitsilis, P. (2019). Educ8 ontology: Semantic modeling of multifacet learning pathways. Education and Information Technologies, 24, 2371-2390.

Ibrahim, M. E., Yang, Y., Ndzi, D. L., Yang, G., \& Al-Maliki, M. (2018). Ontology-based personalized course recommendation framework. IEEE Access, 7, 5180-5199.

Isotani, S., Mizoguchi, R., Isotani, S., Capeli, O. M., Isotani, N., De Albuquerque, A. R., ... Jaques, P. (2013). A semantic webbased authoring tool to facilitate the planning of collabo-rative learning scenarios compliant with learning theories. Computers \& Education, 63, 267-284.

Jovanović, J., Knight, C., Gašević, D., \& Richards, G. (2006). Learning object context on the semantic web. In Sixth international conference on advanced learning technologies, 2006, (pp. 669-673). IEEE.

Kasai, T., Nagano, K., \& Mizoguchi, R. (2011). Instructional design support system based on both theory and practice and its evaluation. In Proceedings of ICCE2011, (pp. 1-8).

Knight, C., Gasevic, D., \& Richards, G. (2006). An ontology-based framework for bridging learning design and learning content. Journal of Eductational Technology and Society, 9, 23.

Koper, R. (2005). An introduction to learning design. In Learning design (pp. 3-20). Springer, Berlin.

Labib, A. E., Canós, J. H., \& Penadés, M. C. (2017). On the way to learning style models integration: A learner's characteristics ontology. Computers in Human Behavior, 73, 433-445.

Lachheb, A., \& Boling, E. (2018). Design tools in practice: Instructional designers report which tools they use and why. Journal of Computing in Higher Education, 30, 34-54.

Lalingkar, A., Ramanathan, C., \& Ramani, S. (2015). Monto: A machine-readable ontology for teaching word problems in mathematics. Journal of Educational Technology and Society, 18(3), 197-213.

Larson, M. B., \& Lockee, B. B. (2019). Streamlined ID: A practical guide to instructional design. Routledge. 
Leo, J., Kurdi, G., Matentzoglu, N., Parsia, B., Sattler, U., Forge, S., ... Dowling, W. (2019). Ontology-based generation of medical, multi-term mcqs. International Journal of Artificial Intelligence in Education, 29, 145-188.

Merrill, M. D. (2012). First principles of instruction. Wiley.

Miranda, S., Orciuoli, F., Loia, V., \& Sampson, D. (2017). An ontology-based model for competence management. Data \& Knowledge Engineering, 107, 51-66.

Mitsis, K., Zarkogianni, K., Bountouni, N., Athanasiou, M., \& Nikita, K. S. (2019). An ontology-based serious game design for the development of nutrition and food literacy skills. In 2019 41st annual international conference of the IEEE Engineering in Medicine and Biology Society (EMBC), (pp. 1405-1408). IEEE.

Mizoguchi, R., \& Bourdeau, J. (2016). Using ontological engineering to overcome ai-ed problems: Con-tribution, impact and perspectives. International Journal of Artificial Intelligence in Education, 26(1), 91-106.

Mizoguchi, R., Hayashi, Y., \& Bourdeau, J. (2007). Inside theory-aware and standards-compliant au-thoring system. In SW-EL'07, (p. 18).

Mizoguchi, R., Vanwelkenhuysen, J., \& Ikeda, M. (1995). Task ontology for reuse of problem solving knowledge. In Towards very large knowledge bases: Knowledge building \& knowledge sharing, (pp. 46-59).

Neven, F., \& Duval, E. (2002). Reusable learning objects: A survey of lom-based repositories. In Proceedings of the tenth ACM international conference on multimedia, (pp. 291-294). ACM.

Nikolas, A., Sotiriou, S., Zervas, P., \& Sampson, D. G. (2014). The open discovery space portal: A socially-powered and open federated infrastructure. In Digital systems for open access to formal and informal learning, (pp. 11-23). Springer, Cham.

Nouira, A., Cheniti-Belcadhi, L., \& Braham, R. (2019). An ontology-based framework of assessment analytics for massive learning. Computer Applications in Engineering Education, 27, 1343-1360.

Noy, N., McGuinness, D. L., et al. (2001). Ontology development 101. Knowledge Systems Laboratory, Stanford University.

Paquette, G. (2014). A competency-based ontology for learning design repositories. International Journal of Advanced Computer Science and Applications, 5, 55-62.

Patel, I. (2002). Information and communication technology and distance adult literacy education in India. Indian Journal of Open Learning, 11(2), 255-268.

Pinto, V. A., de Rezende Rohlfs, C. L., \& Parreiras, F. S. (2014). Applications of ontologies in enterprise modelling: A systematic mapping study. In Advances in conceptual modeling, (pp. 23-32). Springer, Cham.

Piskurich, G. M. (2015). Rapid instructional design. Wiley Online Library.

Psyché, V., Bourdeau, J., Nkambou, R., \& Mizoguchi, R. (2005). Making learning design standards work with an ontology of educational theories. In 12th Artificial Intelligence in Education (AIED2005), (pp. 539-546). IOS Press.

Ram, A., \& Leake, D. B. (1995). Goal-driven learning. MIT Press.

Rodríguez-Artacho, M., \& Maillo, M. F. V. (2004). Modeling educational content: The cognitive approach of the PALo language. Educational Technology \& Society, 7, 124-137.

Sampson, D. G., Lytras, M. D., Wagner, G., \& Diaz, P. (2004). Ontologies and the semantic web for e-learning. Educational Technology \& Society, 7, 26-28.

Sarwar, S., Qayyum, Z. U., García-Castro, R., Safyan, M., \& Munir, R. F. (2019). Ontology based e-learning framework: A personalized, adaptive and context aware model. Multimedia Tools and Applications, 78, 34745-34771.

Selwyn, N. (2020). Telling tales on technology: Qualitative studies of technology and education. Routledge.

Serrano, D. R., Dea-Ayuela, M. A., Gonzalez-Burgos, E., Serrano-Gil, A., \& Lalatsa, A. (2019). Technology-enhanced learning in higher education: How to enhance student engagement through blended learning. European Journal of Education, 54, $273-286$.

Sfar, H., Chaibi, A. H., Bouzeghoub, A., \& Ghezala, H. B. (2016). Gold standard based evaluation of ontology learning techniques. In Proceedings of the 31st annual ACM symposium on applied computing, (pp. 339-346).

Shen, C.-W., \& Ho, J.-T. (2020). Technology-enhanced learning in higher education: A bibliometric analysis with latent semantic approach. Computers in Human Behavior, 104, 106177.

Sicilia, M.-Á., Lytras, M. D., Sánchez-Alonso, S., García-Barriocanal, E., \& Zapata-Ros, M. (2011). Modeling instructional-design theories with ontologies: Using methods to check, generate and search learning designs. Computers in Human Behavior, 27, 1389-1398.

Sowa, J. F. (1999). Knowledge representation: Logical, philosophical, and computational foundations.

Stancin, K., Poscic, P., \& Jaksic, D. (2020). Ontologies in education - state of the art. Education and Information Technologies. https://doi.org/10.1007/s10639-020-10226-z.

Stokić, D., Pata, K., Devedžić, V., Jovanović, J., Urošević, L., Gašević, D., ... Wild, J. (2008). Intelligent learning extended organizations. In Proceedings of TELearn2008.

Tapia-Leon, M., Rivera, A. C., Chicaiza, J., \& Luján-Mora, S. (2018). Application of ontologies in higher education: A systematic mapping study. In 2018 IEEE Global Engineering Education Conference (EDUCON), (pp. 1344-1353). IEEE.

Tebes, G., Peppino, D., Becker, P., Matturro, G., Solari, M., \& Olsina, L. (2019). A systematic review on software testing ontologies. In International conference on the quality of information and communications technology, (pp. 144-160). Springer.

Toyama, K. (2011). There are no technology shortcuts to good education. Educational Technology Debate, 8.

UNESCO (2014). Education for all global monitoring report 2013/4: Teaching and learning: Achieving quality for all. United Nations Educational and Scientific and Cultural Organization.

Uschold, M., \& Gruninger, M. (2004). Ontologies and semantics for seamless connectivity. ACM S/GMod Record, 33, 58-64

Verbert, K., Jovanovic, J., Duval, E., Gasevic, D., \& Meire, M. (2006). Ontology-based learning content repurposing: The alocom framework. International Journal on E-Learning, 5, 67-74.

Verbert, K., Klerkx, J., Meire, M., Najjar, J., \& Duval, E. (2004). Towards a global component architecture for learning objects: An ontology based approach. In On the move to meaningful internet systems 2004: OTM 2004 workshops, (pp. 713-722). Springer, Berlin.

Verón, S., Celeste, V., Alejandra, A. M., \& de los Milagros, G. M. (2016). An interoperability model based on ontologies for learning object repositories. In 2016 International Symposium on Computers in Education (SIIE), (pp. 1-6). IEEE.

Vidal-Castro, C., Sicilia, M.-Á., \& Prieto, M. (2012). Representing instructional design methods using ontologies and rules. Knowledge-Based Systems, 33, 180-194. 
Wang, S., \& Koohang, A. (2009). Ontology of learning objects repository for pedagogical knowledge sharing. International Journal of Doctoral Studies, 4, 1-12.

Wong, W., Liu, W., \& Bennamoun, M. (2012). Ontology learning from text: A look back and into the future. ACM Computing Surveys (CSUR), 44, 20.

Yago, H., Clemente, J., Rodriguez, D., \& Fernandez-de Cordoba, P. (2018). On-smmile: Ontology network-based student model for multiple learning environments. Data \& Knowledge Engineering, 115, 48-67.

Yang, L., Cormican, K., \& Yu, M. (2020). Ontology learning for systems engineering body of knowledge. IEEE Transactions on Industrial Informatics.

\section{Publisher's Note}

Springer Nature remains neutral with regard to jurisdictional claims in published maps and institutional affiliations.

Submit your manuscript to a SpringerOpen ${ }^{\odot}$ journal and benefit from:

- Convenient online submission

- Rigorous peer review

- Open access: articles freely available online

- High visibility within the field

- Retaining the copyright to your article

Submit your next manuscript at $\boldsymbol{\nabla}$ springeropen.com 